\title{
Temperature Dependence of Ultrasonic Waves Properties Propagated in Some Types of Carbon Steels
}

\author{
Luong Thi Minh Thuy ${ }^{1, *}$, Pham Van Thanh ${ }^{1}$, Nguyen Xuan Tuyen ${ }^{1}$, \\ Nguyen Duc Anh ${ }^{1}$, Nguyen Thi Ha Thu ${ }^{2}$ \\ ${ }^{1}$ Faculty of Physics, VNU University of Science, 334 Nguyen Trai, Hanoi, Vietnam \\ ${ }^{2}$ Air Defence - Air Force Academy, Kim Son, Son Tay, Hanoi, Vietnam
}

Received 17 April 2017

Revised 22 May 2017; Accepted 15 June 2017

\begin{abstract}
In this research, properties of ultrasonic waves transmitted in some carbon steels were investigated. Base on ultrasonic measurements for the steel samples of X40H, S45, SCM420, and SCR420, the values of ultrasonic wave velocities including longitudinal and transverse velocities were determined. These measurements also used to obtain ultrasonic attenuations of these steel samples. Based on ultrasonic velocities, the mechanical properties of these steel samples were calculated including Poisson's Ratio v, Young's modulus E, and Shear modulus G. The experimental results show that these mechanical parameters were linearly depended on the carbon steel samples' temperature.
\end{abstract}

Keywords: Carbon steels, Ultrasonic Velocity, Ultrasonic Attenuation, Mechanical Characteristics.

\section{Introduction}

Non-destructive testing (NDT) is a group of analysis method to evaluate properties of materials, components, or system without causing damage of test sample. Especially, they are widely used to check the defects inside components. If a defect appears, its location, dimension and shape could be determined by NDTs. Up to date, there are several techniques of NDTs, such as X-ray images [1], thermographic imaging [2], the ultrasonic testing method [3], etc. Among these techniques, the ultrasonic testing method is widely utilized due to its advantages such as low-cost, high accuracy, short time, and high safety.

Today, carbon steels are used in many fields, especially in the field of industrial application because of their many good properties. They are not only very strong and durable but also tolerable by the heat. Formerly, there are many studies which showed that the ultrasonic nondestructive testing is useful method to characterize the properties of the carbon steels. For example, Yan et al. and Zenghua et al. reported the dependences of the ultrasonic properties of steels on temperature [4,5]. Freitas et al.

\footnotetext{
*Corresponding author. Tel.: 84-978257267.

Email: minhthuyhus@gmail.com

https://doi.org/10.25073/2588-1124/vnumap.4205
} 
showed that the nondestructive characterization of microstructures and determination of elastic properties of the carbon steel can be utilized by the ultrasonic method [6]. Hence, evaluating the properties of carbon steels is very necessary and the ultrasonic non-destructive testing is a reliable method to do this work.

The main aim of this work is to analyze the effect of samples' temperature on the ultrasonic velocities and attenuations in several carbon steel including X40H, S45, SCM420, and SCR420. Based on obtained ultrasonic velocities, the mechanical properties of these samples were determined in detail.

\section{Experimental methods and theory}

In this study, the carbon steel samples with brands of SCM 420, X40H, SCR 420 and S45 were used to characterize with different element contents which were shown in Table 1 . These samples are adjusted with reliable dimensions as shown in Fig.1. Each type of sample separates into 2 parts: one for ultrasonic longitudinal wave measurement and the other for transverse wave measurement. The chemical compositions of these carbon samples are shown in Table 1 in \%wt.

Table 1. Element compositions of carbon steel samples

\begin{tabular}{llllllllll}
\hline $\begin{array}{l}\text { Carbon } \\
\text { steel }\end{array}$ & $\mathrm{C}$ & $\mathrm{Si}$ & $\mathrm{Mn}$ & $\mathrm{P}$ & $\mathrm{S}$ & $\mathrm{Cr}$ & $\mathrm{Ni}$ & $\mathrm{Mo}$ & $\mathrm{Cu}$ \\
& $(\% \mathrm{wt})$ & $(\% \mathrm{wt})$ & $(\% \mathrm{wt})$ & $(\% \mathrm{wt})$ & $(\% \mathrm{wt})$ & $(\% \mathrm{wt})$ & $(\% \mathrm{wt})$ & $(\% \mathrm{wt})$ & $(\% \mathrm{wt})$ \\
\hline $\mathrm{X} 40 \mathrm{H}$ & $0.37-0.44$ & $0.17-0.37$ & $0.5-0.8$ & $\leq 0.035$ & $\leq 0.035$ & $0.8-1.0$ & $\leq 0.3$ & & $\leq 0.03$ \\
S45 & $0.42-0.48$ & $0.15-0.35$ & $0.6-0.9$ & 0.03 & 0.03 & $\leq 0.2$ & $\leq 0.2$ & $\leq 0.3$ \\
SCM420 & $0.18-0.23$ & $0.15-0.35$ & $0.6-0.9$ & 0.03 & 0.03 & $0.9-1.2$ & $\leq 0.25$ & $0.15-0.25$ & $\leq 0.3$ \\
SCR420 & $0.18-0.23$ & $0.15-0.35$ & $0.6-0.9$ & 0.03 & 0.03 & $0.9-1.2$ & $\leq 0.25$ & & 0.3 \\
\hline
\end{tabular}

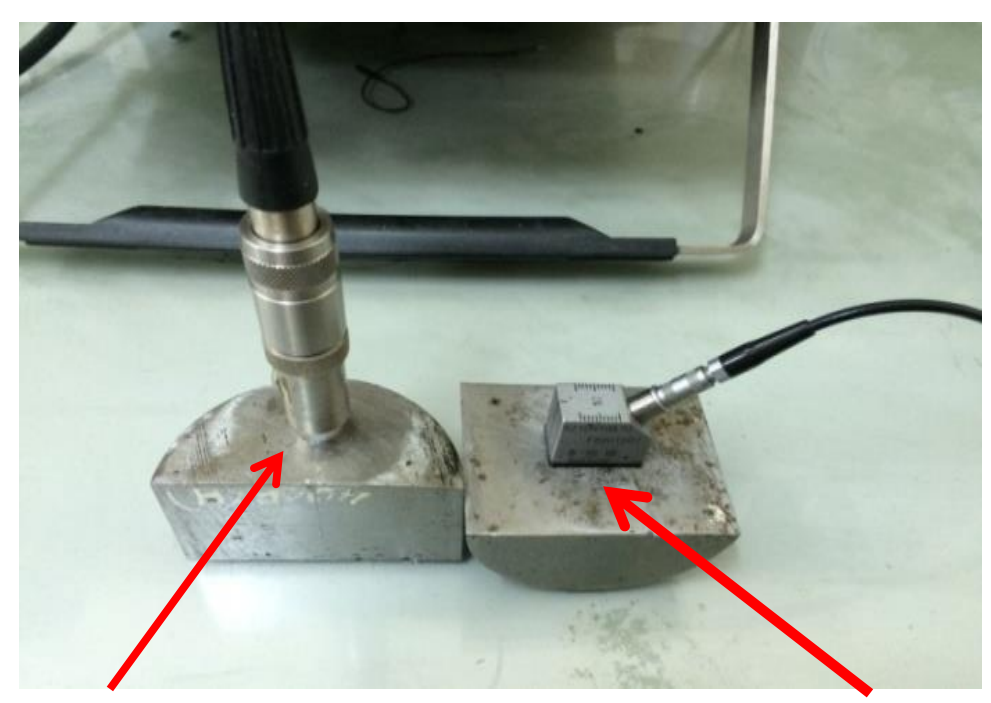

Ultrasonic longitudinal measurements

Ultrasonic transverse measurements

Figure 1. The shapes of the steel samples in the experimental. 


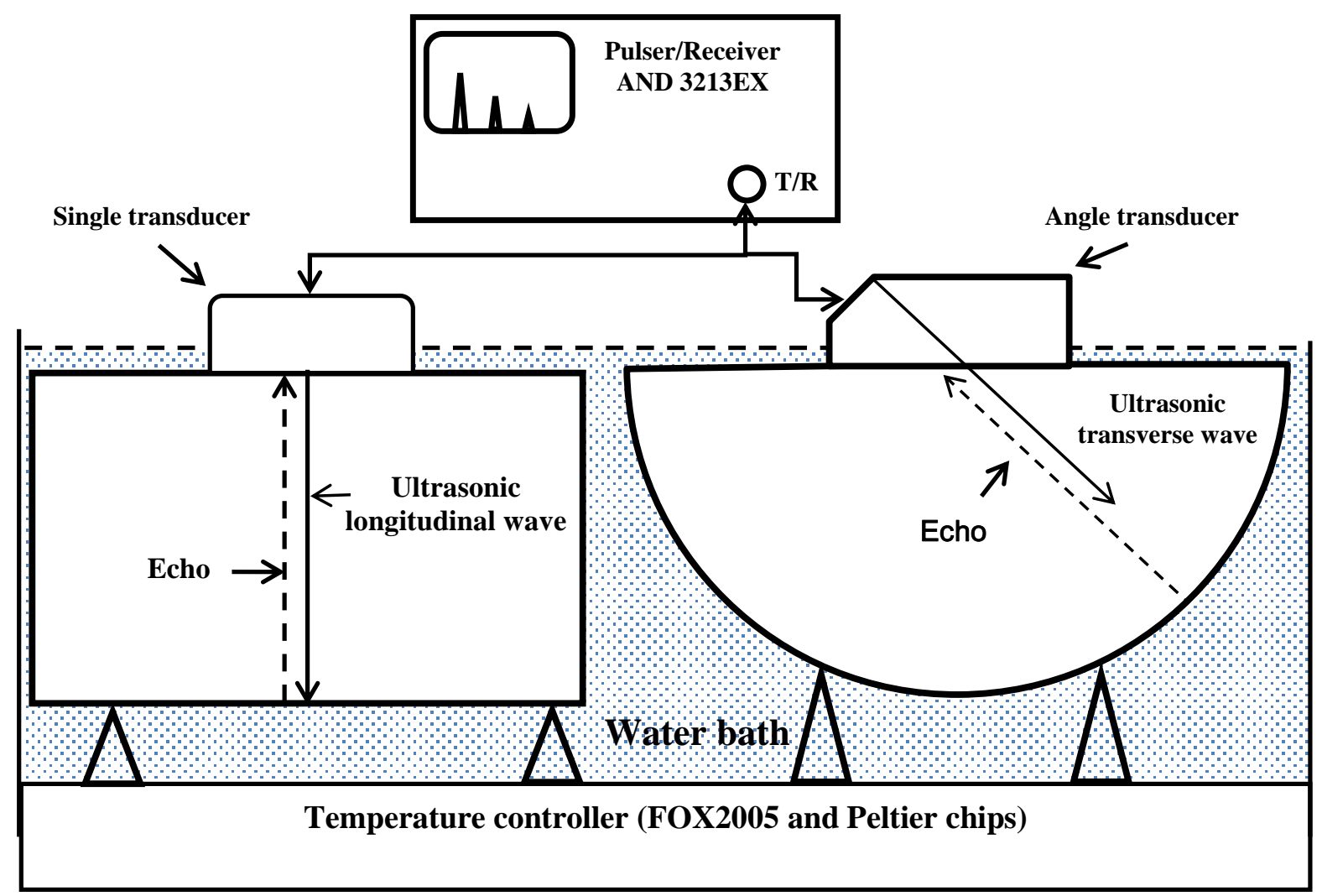

Figure 2. The diagram set-up to investigate the ultrasonic properties of the steel samples.

In this study, the ultrasonic longitudinal wave was generated and then received echoes by using single ultrasonic transducer with $5 \mathrm{MHz}$ center frequency; while ultrasonic transverse wave were generated by 70 angle ultrasonic transducer with $5 \mathrm{MHz}$ center frequency. Motor oil was utilized as a coupling material between ultrasonic transducers and testing samples in order to helps the ultrasonic wave propagating into the test sample [7]. The testing samples were put inside water bath and their temperature was controlled by a temperature controller FOX2005 and Peltier chips with $\pm 0.5^{\circ} \mathrm{C}$ of temperature variation. The sample's temperature changed in the range from 0 to $50{ }^{\circ} \mathrm{C}$ with $5{ }^{\circ} \mathrm{C}$ for each raising step. The waiting time for each step is about 20 mins in order to obtain temperature's stability. This sample's temperature must be kept smaller than $55^{\circ} \mathrm{C}$ because the ultrasonic transducers could be damaged at high temperature [8].

For each sample, a transducer was used to generate an ultrasonic wave and then received echo signals from bottom of testing samples. Two adjacent echoes signals were obtained and the propagated time between them was measured. The samples' thicknesses were measured by using Vernier Caliper with accuracy of $\pm 0.02 \mathrm{~mm}$. And then, the ultrasonic velocity propagated in the testing samples was determined as following:

$$
C=\frac{2 d}{t}
$$

In which $d$ is the thickness of sample, $t$ is the time of the propagation.

Ultrasonic attenuation coefficient was calculated from the process of reducing of the peak amplitude of the ultrasound echo, as following 


$$
\alpha=\frac{-20}{2(m-n) d} \log \left(\frac{I_{m}}{I_{n}}\right)
$$

Where $I_{n}$ and $I_{m}$ are the maximum amplitude of the $\mathrm{m}^{\text {th }}$ and $\mathrm{n}^{\text {th }}$ pulse echoes.

The mechanical properties of steel samples will change because of the temperature of them. A linear dependence of the property on temperature is assumed through equation $[5,9,10]$ :

$$
P(T)=P\left(T_{0}\right)+\frac{\partial P(T)}{\partial T} \Delta T
$$

Where $\mathrm{P}$ is one of the mechanical properties of sample such as Young's modulus E, Poisson's Ratio v, shear modulus G, T is sample's temperature, $\mathrm{T}_{0}$ is reference temperature, and $\frac{\partial P(T)}{\partial T}$ is temperature dependence coefficient.

In addition, the dependence of ultrasonic wave velocities on temperature can be obtained by following relations $[6,10]$

$$
\begin{gathered}
C_{l}=\sqrt{\frac{E(1-v)}{\rho(1+v)(1-2 v)}} \\
C_{t}=\sqrt{\frac{E}{2 \rho(1+v)}}=\sqrt{\frac{G}{\rho}}
\end{gathered}
$$

In which $C_{l}$ and $C_{t}$ are the longitudinal and transverse wave velocities, respectively, $\rho$ is the mass density of material, $v$ is Poisson's Ratio; E and $G$ is the Young's modulus and shear modulus, respectively.

Based on Eq. (4) and Eq. (5), Young's modulus E, Poisson's Ratio v, and shear modulus G could be expressed as following:

$$
\begin{aligned}
& v=\frac{C_{l}^{2}-2 C_{t}^{2}}{2\left(C_{l}^{2}-C_{t}^{2}\right)} \\
& E=\frac{\rho C_{t}^{2}\left(3 C_{l}^{2}-4 C_{t}^{2}\right)}{C_{l}^{2}-C_{t}^{2}} \\
& G=\rho C_{t}^{2}
\end{aligned}
$$

Because the ultrasonic wave velocities depend on temperature, the values of $v$, E, and G could be also effected by the sample's temperature $[11,12]$.

\section{Results and discussion}

The experimental values of the ultrasonic longitudinal waves with $5 \mathrm{MHz}$ center frequencies of ultrasonic transducer for the steel samples with brand of S45, X40H, SCM420, and SCM420 at room temperature are presented in Table 2 . The experimental results showed that the longitudinal velocities are in the range from $5892 \pm 1$ to $5937 \pm 1 \mathrm{~m} / \mathrm{s}$. The experimental transverse velocities of these steel samples with $5 \mathrm{MHz}$ center frequency of angle ultrasonic transducer were also determined, and their values are in the range from $3220 \pm 1$ to $3321 \pm 1 \mathrm{~m} / \mathrm{s}$. Notably, the experimental values of 
ultrasonic velocities are different sample by sample. Because the experimental ultrasonic velocities were sensitive to mechanical properties of testing samples as shown in Eq. (4)-(5), it could be predicted that the moduluses of these samples are also different due to the dissimilarity of the element compositions of each steel sample (Table 1). Additionally, we can see the same behavior in all frequencies used and these experimental values are closed to previous study [6], which allows us to conclude that these results are reliable.

Table 2. Ultrasonic velocity measurements for longitudinal waves and for transverse waves at room temperature

\begin{tabular}{lll}
\hline Carbon steel & $\begin{array}{l}\text { Transverse Velocity } \\
C_{t}(\mathrm{~m} / \mathrm{s})\end{array}$ & $\begin{array}{l}\text { Longitudinal Velocity } \\
C_{l}(\mathrm{~m} / \mathrm{s})\end{array}$ \\
\hline X40H & $3249 \pm 1$ & $5920 \pm 1$ \\
S45 & $3223 \pm 1$ & $5915.5 \pm 1$ \\
SCM420 & $3260 \pm 1$ & $5908 \pm 1$ \\
SCR420 & $3321 \pm 1$ & $5934 \pm 1$ \\
\hline
\end{tabular}
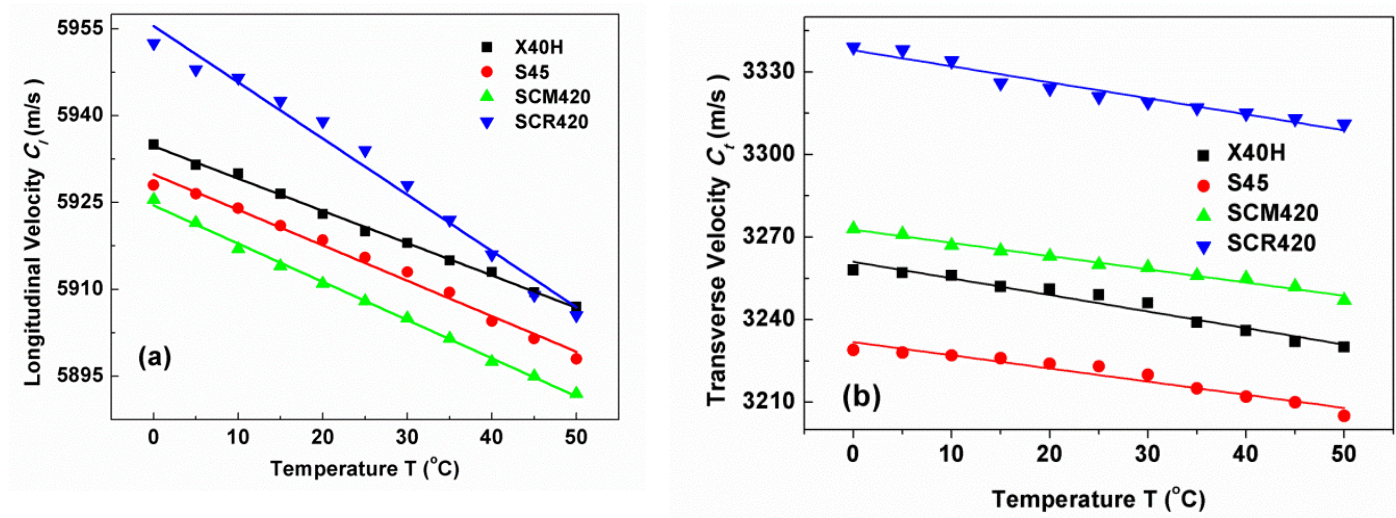

Figure 3. Effect of temperature on (a) longitudinal velocities $C_{1}$, (b) transverse ones $C_{t}$ transmitted in the carbon steel samples

Figure 3 shows the dependence of the ultrasonic velocities transmitted in the samples on temperature. All longitudinal velocities increased in the range from $5891 \pm 1$ to $5953 \pm 1 \mathrm{~m} / \mathrm{s}$ when sample's temperature decreased from 50 down to $0{ }^{\circ} \mathrm{C}$ (Figure 3 (a)). Simultaneously, the ultrasonic transverse velocities $C_{t}$ are also raised from $3205 \pm 1$ to $3338 \pm 1 \mathrm{~m} / \mathrm{s}$ in this temperature range (Figure 3 (b)). These experimental values are comparable with ones of other researches for carbon steel [4-6, 13], hence these experimental results are reliable.

It is clearly observed that these velocities are linearly dependent on temperature as descripted in Eq. (3). By using linear fitting of experimental velocities, the temperature dependences of these velocities were estimated as linear-lines $\left(\mathrm{R}^{2}=0.979 \sim 0.997\right)$ shown in Figure 3 (a) and Figure 3 (b) for the longitudinal and transverse ultrasonic wave in sequence. The longitudinal temperature dependent coefficients were calculated to be $-0.56,-0.61,-0.66$, and $-0.97 \mathrm{~m} / \mathrm{s} .{ }^{\circ} \mathrm{C}$ for X $40 \mathrm{H}, \mathrm{S} 45, \mathrm{SCM} 420$ and SCR420, respectively. Instantaneously, the temperature dependent coefficients of transverse velocities were also determined to be $-0.48,-0.58,-0.60$, and $-0.4897 \mathrm{~m} / \mathrm{s} .{ }^{\circ} \mathrm{C}$ for $\mathrm{X} 40 \mathrm{H}, \mathrm{S} 45, \mathrm{SCM} 420$ and SCR420, respectively. 

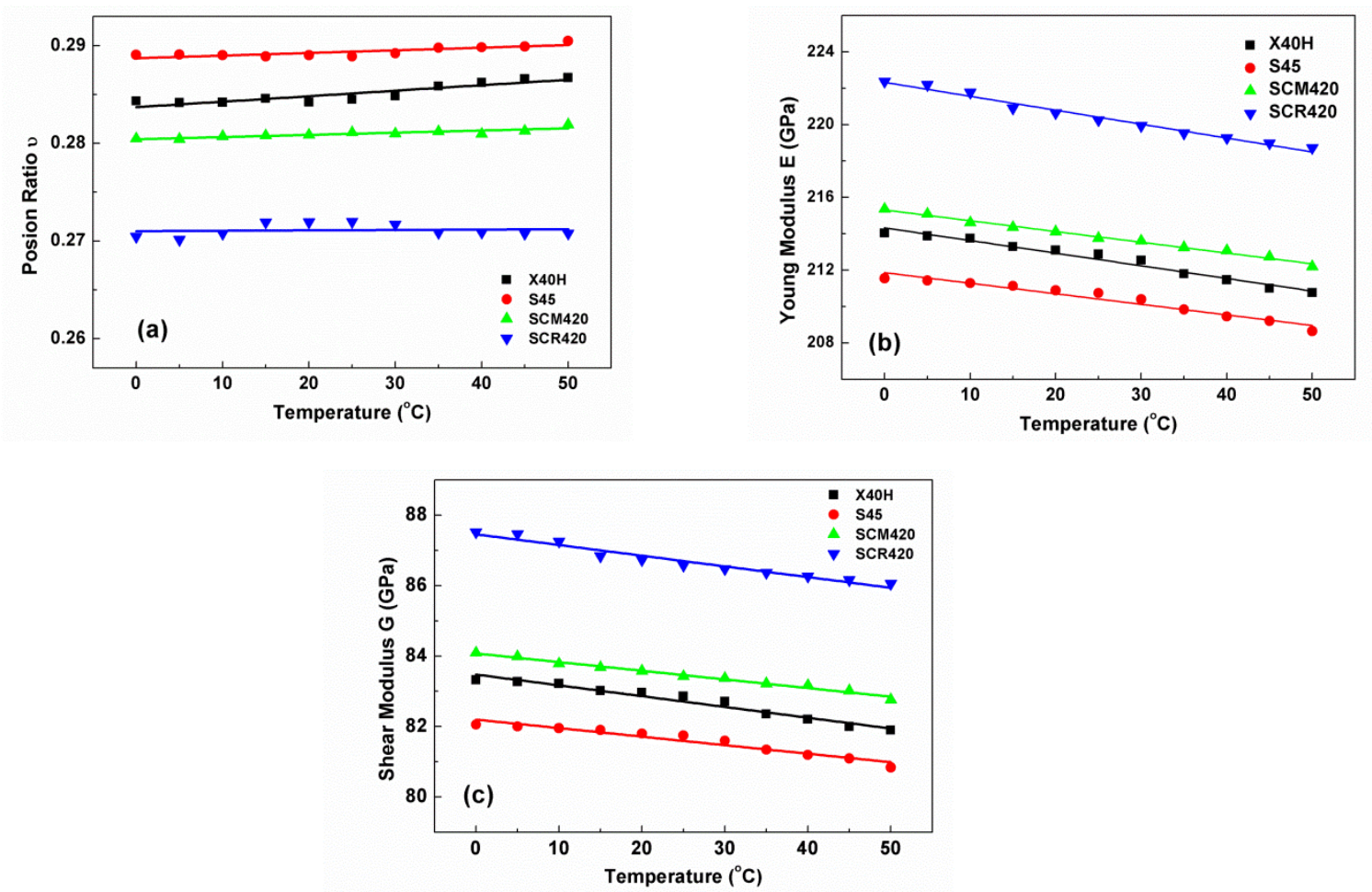

Figure 4. Temperature dependence of (a) Poisson's ratio v, (b) Young's modulus E, and (c) Shear modulus $G$ of the steel samples.

Furthermore, based on the measured velocities and Eq. (6), (7), (8), the dependence of mechanical properties of these carbon steel samples on samples' temperatures are estimated that include Poisson's Ratio v, Young's modulus E and the Shear modulus G of the testing steel samples. These dependences are shown in the Figure 4 with samples' temperature decreasing from 50 down to $0{ }^{\circ} \mathrm{C}$.

The calculated values of Poisson's ratio $v$ were in the range from 0.270 to 0.287 when temperature increasing from 0 to $50{ }^{\circ} \mathrm{C}$ (Figure 4 (a)). These values were very close to 0.29 of Poisson's ratio of the typical steels [11]. The values of Young's modulus E were determined in the range from 208.6 to 222.4 GPa. It is clear that these Young's modulus E are linear with samples' temperature (Figure 4 (b)). This rate is close to one of $-0.06 \mathrm{GPa} /{ }^{\circ} \mathrm{C}$ of the low carbon steel by American Society for Metals [11]. Furthermore, the values of Shear modulus $\mathrm{G}$ were calculated in the range from 80.8 to $87.5 \mathrm{GPa}$ and linear dependence on the sample's temperature (Figure 4 (c)). These obtained values of $\mathrm{E}$ and $\mathrm{G}$ are very close to ones of the low carbon steel investigated by previous researches $[11,14,15]$. By using linear fitting of the obtained values of $v, E$, and $G$; the estimated temperature dependent coefficients of these mechanical characteristics were described as in Table 3 for each steel samples with good linearity $\left(\mathrm{R}^{2}=0.90 \sim 0.96\right)$.

Additionally, by using Eq. (2) for echo-peaks of pulse-echo technique, the average values of ultrasonic attenuations in these steel samples were considered for longitudinal waves. The calculated values of the attenuations vs. samples' temperature are presented in Figure 5. It is clearly observed that 
these attenuations were decreased in the range from 0.86 to $0.37 \mathrm{~dB} / \mathrm{cm}$ when the sample's temperature increased from 0 to $50^{\circ} \mathrm{C}$. The dependence of these attenuations on temperature is very complicated to explain. In this research, it is believed that they are strongly dependence on properties of motor oil that was used as a coupling material between ultrasonic transducer and testing sample. At low temperature, the ultrasonic attenuation of motor oil is larger leading to the larger absorption coefficient of ultrasound propagated in the steel sample. At high temperature, it is smaller, hence the ultrasonic attenuation is also small [7].

Table 3. Temperature dependent coefficients of Poisson's ratio v, Young's modulus E, and Shear modulus G estimated by linear fitting

\begin{tabular}{llll}
\hline \multirow{2}{*}{ Carbon steel } & \multicolumn{3}{l}{ Temperature dependent coefficients } \\
\cline { 2 - 4 } & Poisson's ratio v & $\begin{array}{l}\text { Young's modulus E } \\
\left(\mathrm{GPa} /{ }^{\circ} \mathrm{C}\right)\end{array}$ & $\begin{array}{l}\text { Shear modulus } \mathrm{G} \\
\left(\mathrm{GPa} /{ }^{\circ} \mathrm{C}\right)\end{array}$ \\
\hline $\mathrm{X} 40 \mathrm{H}$ & $5.63 \times 10^{-5}$ & -0.070 & -0.031 \\
$\mathrm{~S} 45$ & $2.69 \times 10^{-5}$ & -0.058 & -0.024 \\
$\mathrm{SCM} 420$ & $2.24 \times 10^{-5}$ & -0.059 & -0.025 \\
$\mathrm{SCR} 420$ & $3.85 \times 10^{-6}$ & -0.077 & -0.030 \\
\hline
\end{tabular}

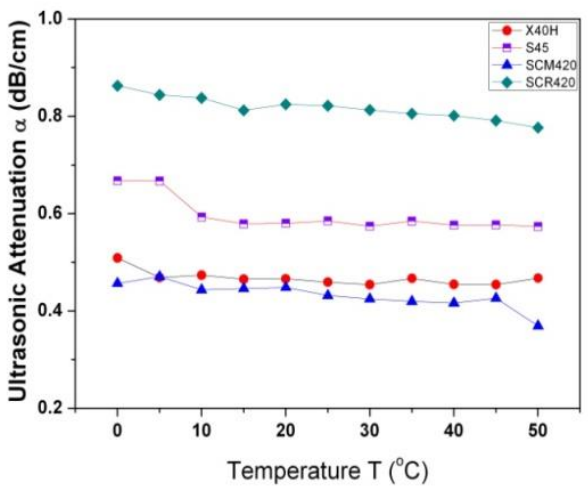

Figure 5. Attenuation of ultrasound transmitted in the samples.

\section{Conclusions}

In this research, an evaluation of ultrasonic testing, mainly by considering ultrasonic velocity and attenuation measurements, was presented. After analyzing the results, we can to conclude:

1. For the samples studied and the frequencies adopted, the ultrasonic measurements show that four samples with different element contents led to different ultrasonic velocity. In other words, ultrasonic measurements are also directly related to the element contents of the carbon steel and that is a good measurement method to determine the properties of the carbon steel with brand of $\mathrm{X} 40 \mathrm{H}, \mathrm{S} 45$, SCM420 and SCR420.

2. The dependences of ultrasonic velocities and attenuations on temperature were determined for each carbon steel sample. When the samples' temperature raised from 0 to $50^{\circ} \mathrm{C}$, the ultrasonic velocities were linearly decreased for all testing carbon steel samples. The ultrasonic attenuations were 
also decreased with increasing of sample's temperature due to the effect of temperature on the properties of motor oil that used as coupling material.

3. Furthermore, the mechanical characteristics of these steel samples including Poisson's ratio $v$, Young's modulus E, and Shear modulus G were determined. These mechanical characteristics are linearly dependent on samples' temperature in the range from 0 to $50{ }^{\circ} \mathrm{C}$. It is concluded that the temperature effects very much on mechanical characteristics of carbon steel. Therefore, we need consider the temperature of sample in order to improve the accuracy of the nondestructive ultrasonic method for estimating the mechanical properties of carbon steel.

\section{Acknowledgments}

The author thanks the financial support given by Project No. TN-16-06 of VNU University of Science - Vietnam National University Hanoi.

\section{References}

[1] Albuquerque, V.H.C.D., J.M.R.S. Tavares, and L.M.P. Durão, Evaluation of Delamination Damage on Composite Plates using an Artificial Neural Network for the Radiographic Image Analysis. Journal of composite materials, 2010. 44(9): p. 1139-1159.

[2] Mabrouki, F., M. Genest, G. Shi, and A. Fahr, Numerical modeling for thermographic inspection of fiber metal laminates. NDT \& E International, 2009. 42(7): p. 581-588.

[3] Schmerr, L. and J.-S. Song, Ultrasonic Nondestructive Evaluation Systems: Models and Measurements. 1 ed2007, 233 Spring Street, New York, NY 10013, USA: Springer US.

[4] Yan, C., W. Guan, Z. Gao, W. Chen, and Y. Tao, Ultrasonic shear wave testing of pressurized components at high temperature. Journal of Pressure Equipment and Systems, 2005. 3: p. 54-57.

[5] Zenghua, L., Z. Jichen, W. Bin, and H. Cunfu, Temperature Dependence of Ultrasonic Longitudinal Guided Wave Propagation in Long Range Steel Strands. Chinese journal of mechanical engineering, 2011. 24(3): p. $487-$ 494.

[6] Freitas, V.L.d.A., V.H.C.d. Albuquerque, E.d.M. Silva, A.A. Silva, and J.M.R.S. Tavares, Nondestructive characterization of microstructures and determination of elastic properties in plain carbon steel using ultrasonic measurements. Materials Science and Engineering: A, 2010. 527(16-17): p. 4431-4437.

[7] Thanh, P.V., P.T.T. Nhung, L.T.M. Thuy, and N.H. Nhai, Effect of temperature on ultrasonic velocities, attenuations, reflection and transmission coefficients between motor oil and carbon steel estimated by pulse-echo technique of ultrasonic testing method. VNU Journal of Science: Mathematics - Physics, 2015. 31(4): p. 39-48.

[8] Olympus. Ultrasonic Transducers. Available from: http://www.olympus-ims.com/en/ultrasonic-transducers/.

[9] Lanza di Scalea, F. and S. Salamone, Temperature effects in ultrasonic Lamb wave structural health monitoring systems. The Journal of the Acoustical Society of America, 2008. 124(1): p. 161-174.

[10] Dodson, J.C. and D.J. Inman, Thermal sensitivity of Lamb waves for structural health monitoring applications. Ultrasonics, 2013. 53(3): p. 677-85.

[11] Committee, A.I.H., Properties and selection: irons, steels, and high-performance alloys. Vol. 1. 1990: ASM International.

[12] Arridge, R.G.C., A new method for measurement of bulk modulus of solid polymers. Journal of Physics E: Scientific Instruments, 1974. 7(5): p. 399.

[13] Ruiz, A., N. Ortiz, A. Medina, J.Y. Kim, and L.J. Jacobs, Application of ultrasonic methods for early detection of thermal damage in 2205 duplex stainless steel. NDT \& E International, 2013. 54: p. 19-26.

[14] Bauccio, M., ASM Metals Reference Book. 3rd ed1993, Materials Park, OH: ASM International.

[15] Davis, J.R., ASM Specialty Handbook - Carbon and Alloy Steels1996, Metals Park, OH: ASM International. 